\title{
Considering Context in Psychological Leadership Research
}

Robert C. Liden

Department of Managerial Studies

University of Illinois at Chicago

John Antonakis

Faculty of Business and Economics

University of Lausanne, Switzerland

Forthcoming in Human Relations, special issue on the context of leadership. 


\title{
Considering Context in Psychological Leadership Research
}

\begin{abstract}
Despite Lewin's identification of the importance of context in behavioral research over 70 years ago, leadership psychology tended to ignore the context. Only in the past 10 years has the context been more routinely included in psychological leadership research. We provide examples of leadership research that has explored the context, introduce the special issue articles, and provide suggestions for future research on the context of leadership.
\end{abstract}




\section{Considering Context in Psychological Leadership Research}

Although the context has been acknowledged as salient to leadership for decades, only in recent years has empirical research given the context widespread attention. This special issue is devoted to the continuation and extension of this interest in organizational studies utilizing a multi-theoretical lens that includes leadership psychology and more discursive, social constructionist approaches to leadership. Because the two approaches represent such divergent ways of examining the context, this special issue is introduced with two separate introductory articles. This article concerns itself with leadership psychology and related approaches.

The context of leadership is the milieu--the physical and social environment--in which leadership is observed. Contexts vary; as such they are measurable and must be modeled when attempting to explain a particular aspect of the leadership puzzle. An important criterion that Dubin (1976) identified for theory building was the boundary conditions (i.e., the context, including space and time) under which a theory is expected to hold (see also Bacharach, 1989). As such, scholars must consider context in leadership research, such as by examining the way context influences the variability that may emerge in the constructs under study or by assessing how context can moderate relations between variables.

Organizational contexts have been identified by many scholars as being critical determinants of the behavior that takes place within organizations (e.g., (Johns, 2001); Johns, 2006; Rousseau, 1985; Rousseau \& Fried, 2001). The importance of context has also been addressed by leadership psychology researchers (Antonakis, Avolio, \& Sivasubramaniam, 2003; Antonakis, Schriesheim et al., 2004; Blair \& Hunt, 1986; 
Dienesch \& Liden, 1986; Erdogan \& Liden, 2002; Liden, Sparrowe, \& Wayne, 1997; Porter \& McLaughlin, 2006; Schriesheim, Castro, \& Cogliser, 1999; Shamir \& Howell, 1999; Zaccaro \& Klimoski, 2001). We begin with a brief overview of approaches to the context that have been taken in the past, including trail blazing research by researchers including Lewin, Fiedler, House, and Mitchell, as well as the interactional psychology approach introduced in the 1980 s to the organizational sciences. Next is a discussion of the contextual role played by national and organizational culture and the team context in leadership research. We then discuss the integration of social network analysis in leadership research and address the implications of the rapid increase in the use of multilevel analyses, such as hierarchical linear modeling, to bringing the context to the study of leadership. After introducing the special issue articles, we present suggestions for furthering the investigation of the context of leadership.

\section{Early Examples of Context in the Behavioral Sciences}

Perhaps most noteworthy in first bringing the context to organizational research is the work of Kurt Lewin, whose famous (Lewin \& Lippitt, 1938) observation that behavior is a function of person and environment provided the impetus for subsequent work advocating that behavior cannot be fully understood without consideration of the situation in which the person or persons are embedded. Interestingly, Lewin's lead article in the very first issue of Human Relations (Lewin, 1947) focused on systems theory applications to the social sciences. Acknowledgement of the situation was made by other early theorists as well, such as Weber (1947) in his theory of charisma, but Lewin's work stands at the forefront of research exploring the interaction between person, context, and behavior. 
An early empirical adaptation of Lewin's pronouncement in the leadership literature was the contingency model developed by Fiedler (1967). Fiedler proposed that rather than the existence of a "best" leadership style, the effectiveness of a style was dependent on the context. Although Fiedler's contingency theory has been controversial (Graen, Alvares, Orris, \& Martella 1970; Vecchio, 1977; C. A. Schriesheim \& Kerr, 1977; C.A. Schriesheim, Tepper, \& Tetrault, 1994), it is undisputed that Fiedler made an important contribution to the leadership literature by highlighting that leadership does not take place in a vacuum- rather, the context must be considered. Another early example of the context being considered in leadership is the path-goal theory developed by House and Mitchell (1974). Whereas Fiedler advocated that leadership style is a stable individual characteristic and that leaders must be assigned to situations fitting their leadership style, House and Mitchell argued that leaders are capable of altering their styles to fit the situation. For example, leaders might provide more direction for subordinates working on unstructured tasks relative to those engaged in structured tasks. House and Mitchell's (1974) testable frameworks led to much empirical work on what were termed "contingency" leadership theories at that time; however, interest in contextual perspectives of leadership waned as charismatic-transformational leadership theories were pushed to the fore. Currently, contextual perspectives are re-emerging in more sophisticated process models (see Antonakis, Cianciolo, \& Sternberg, 2004 for a historical overview of the changes in research streams). For example, hybrid approaches are being developed linking traits with behaviors in particular contexts (Lim \& Ployhart, 2004; Zaccaro, Kemp, \& Bader, 2004).

\section{Interactional Psychology}


Emerging from the person-situation debate in psychology (Epstein, 1980; Mischel, 1977) came a new framework arguing that both person and situation are important. Although related to Lewin's earlier arguments, this new approach, which came to be known as interactional psychology, was unique because it stressed that person and situation reciprocally influence one another (Endler \& Magnusson, 1976). Adapting this approach to the organizational sciences, researchers argued for an interactional psychology approach to study employee behavior in organizations (Schneider, 1983; Terborg, 1981). The key argument was that behaviors in organizations cannot be fully understood when examined in isolation of the context in which they occurred. Consistent with the widespread acceptance of interactional psychology as applied to organizational behavior, empirical research began to examine the interplay between context and individual attitudes and behaviors (Hanges, Schneider, \& Niles, 1990; James \& James, 1989; Ostroff, 1992).

The interactional psychology paradigm is especially salient for understanding the context surrounding leadership; quite simply put, context constrains what behaviors are considered prototypical (Lord, Brown, Harvey, \& Hall, 2001; Lord, Foti, \& De Vader, 1984). The "stronger" the situation, the more salient norms are that guide behavior (Mischel, 1977). For example, in military organizations, strong norms, strict rules, and procedures over-determine behavior (the situation is strong), whereas in relatively weak situations substantial variation in individual behaviors may occur (Antonakis et al., 2003; Antonakis \& House, 2002). Important to note is that not only do individuals do as the situation demands they should, but they have, in the first instance selected those environments and are active players in shaping them (see Schneider, 1987), particularly 
when they are leaders (Sashkin, 2004). In studying how the full-range leadership model is contextually sensitive, Antonakis et al. (2003) examined the covariation of leadership styles of a multifactor theory across various contexts. They found that leader styles were inextricably rooted in contexts; what two factors may positively covary in one context may negatively covary in another. In a similar interactionist vein, leader hierarchical level (or different conceptualizations of leader distance) affects what leader behavior are expected and can be demonstrated, how the leader is legitimized, or the processes by which leaders influence individual, group, or organizational outcomes (Antonakis \& Atwater, 2002; Shamir, 1995; Waldman, 1999).

An easier way to see the impact of context on leadership is to demonstrate how the relation between two variables (e.g., leader style and leader outcomes) changes as a function of context (the moderator), as is oftentimes shown in meta-analyses (where relations across multiple contexts are observed; refer to our later discussion on methodological implications). For example, although transformational leadership, in general, was positively related to leader effectiveness, Lowe, Kroeck, \& Sivasubramaniam (1996) found that relationships between transformational leadership and leader effectiveness were significantly stronger in public than private sector organizations.

\section{National and Organizational Culture}

Since about 1995, there has been a dramatic increase in the amount of research conducted on both organizational and national culture, including investigations exploring the cultural influences on leadership. This globalization of research represents a welcome trend in organizational behavior and leadership in particular. Researchers from around the 
world are now consistent contributors to knowledge, and research samples come from across the globe (Dickson, Den Hartog, \& Mitchelson, 2003). Perhaps the most noteworthy of these attempts has been the GLOBE project led by Robert House (House, Hanges, Javidan, Dorfman, \& Gupta, 2004). This ambitious project has assessed leadership across 62 countries and provided researchers with valuable benchmark data. Evidence from this project to date suggests that there are more similarities across national cultures than differences in terms of the correlates of leader behaviors (also see Bass, 1997; Gelfand, Erez, \& Aycan, 2007). Even though mean levels on many variables differ considerably across national cultures, relationships between variables tend to be remarkably similar. A decade earlier Bass (1997) similarly noted that the key tenets of transactional/transformational leadership have been supported across numerous countries. The global economy, internet, and dramatic growth in international travel may serve to further increase the degree of similarity in patterns of relationships across countries. Although mean levels differ between countries on cultural variables, such as collectivism/individuals, power distance, strong versus weak contexts, within country variability exists, especially in those with great demographic diversity such as the United States. We contend that studies of underlying cultural variables, as they influence individual members of countries, may be more productive than simply comparing countries. Such an approach offers promise in the specification of key latent constructs that underlie differences between countries. One promising approach is to treat culture as a moderator of relationships between leadership and outcomes (Gelfand et al., 2007; Dorfman et al., 1997). 
Advances have also been made in the integration of organizational culture in leadership research. O'Reilly, Chatman, \& Caldwell (1991) identified four dimensions of organizational culture that classify groups of values specifically related to internal organizational activities. Innovation refers to the degree to which risk taking and experimentation are valued, and formal rules are less stressed within organizations. Respect for People is the extent to which respect for individuals and fairness are values shared by organizational members. Aggressiveness describes organizational members' acceptance of assertive and competitive behaviors. Finally, Team Orientation refers to values that promote collaboration, strong interpersonal relationships, group harmony, and individual sacrifice for the benefit of the team. The values that are present within a workgroup prescribe how individuals within a group should behave. As such, they become the standards by which individuals measure the acceptability of each other's words and actions. When leaders and subordinates engage in behaviors that correspond with the values espoused by their workgroups, they are viewed as more effective. For example, it has been discovered that the quality of leader-member exchange (LMX) relationships is relatively less important to individuals employed in organizations with "respect for people" cultures as opposed to cultures characterized as having "aggressive cultures" (Erdogan, Liden, \& Kraimer, 2006). Similarly, collectivists, who focus most on what is best for the group rather than themselves personally, are less concerned about the quality of their LMX relationships than are individuals working in "individualistic" cultures (Erdogan \& Liden, 2006).

Although our focus here is on the exploration of the ways in which context influences leadership and relationships between leaders and followers, it is crucial to 
acknowledge that leaders, especially those at high levels of the organization, such as CEOs and top management team (TMT) members, may play a key role in determining the culture of the organization (Tsui, Zhang, Wang, Xin, \& Wu, 2006). The influence of founding CEOs' leadership on the culture of the organization appears to be especially salient (Ling, Simsek, Lubatkin, \& Veiga, 2008; Schneider, 1987; Schein, 1990; Schneider, Goldstein, \& Smith, 1995). Consistent with evidence supporting both the influence of culture on leadership and leadership on culture, it may be best to portray leadership and culture as being reciprocally related.

\section{Team Context}

Leadership also affects and is affected by the team context. For example, Cogliser and Schriesheim (2000) demonstrated using within and between analyses (WABA) that LMX showed within and between effects for a range of variables including cohesiveness, job challenge, stress, autonomy, leader power, and group cooperation. Similarly, Morgeson and DeRue (2006) found that the urgency of incidents facing the work group was significantly related to the amount of time leaders devoted to managing the event. It has also been discovered that disruptions in events that are important to groups interact with leader behavior in determining leader effectiveness (Morgeson, 2005). For example, the more leaders actively intervene in cases of event disruption, the higher their effectiveness, yet the same level of intervention on the part of leaders is associated with lower effectiveness in situations of low event disruption.

Just as leadership is influenced by the team context, leaders influence teams as well. For example, transformational leadership is positively related to team potency and team performance (Bass, Avolio, Jung, \& Berson, 2003; Lester, Meglino, Korsgaard, 
2002). Leaders can also influence the nature of relationships between subordinates as illustrated by a study in which it was discovered through social network analysis that coworkers tended to trust peers who were trusted by the leader (Lau \& Liden, 2008). Similarly, coworkers tend to have better relationships with peers who have higher quality LMX relationships with the leader (Sherony \& Green, 2002).

A new dimension to leadership research that has just begun to unfold is the exploration of the effects of leader differentiation between subordinates on individual and group outcomes (Henderson, Liden, Glibkowski, \& Chaudhry, 2009). Surprisingly, for decades, research on LMX, an approach to leadership based on the premise that leaders form relationships of differing quality with each subordinate, proceeded without any examination of the outcomes of differentiation on individual or group outcomes. Recently we have learned that team conflict is highest in groups having high levels of LMX differentiation combined with a low mean level of LMX in the work group. (Boises \& Howell, 2006). These researchers also found that team potency increased rapidly the higher the mean LMX and the higher the differentiation. It has also been discovered that group performance tends to be highest in groups with high differentiation and high levels of task interdependence (Liden, Erdogan, Wayne, \& Sparrowe, 2006).

Several investigators have demonstrated that the relationship that leaders have with one follower influences the relationships with other followers. Graen, Liden, and Hoel (1982) reasoned that beyond raw LMX, a group member's relative LMX standing in the work group is salient with respect to outcomes, such as decisions to leave the organization. They operationalized relative LMX as mean LMX in a work group minus each focal group members' individual LMX score and found that relative LMX showed a 
significant negative relationship with turnover, measured one year following the measurement of LMX. Using this approach and using RLMX as a label for relative LMX, Henderson, Wayne, Shore, Bommer, and Tetrick's (2008) results revealed that RLMX explained variance in psychological contract fulfillment and organizational citizenship behaviors (OCBs) beyond variance explained by raw LMX. In a similar vein, research has demonstrated that idiosyncratic deals negotiated between the leader and a follower influence the attitudes of other followers (Lai, Rousseau, \& Chang, in press), causing the follower receiving the special arrangement to engage in greater levels of OCBs (Anand, Vidyarthi, Liden, \& Rousseau, in press). In sum, these studies demonstrated the influence that the social context of teams can have on individual attitudes and behaviors.

Other research relevant to the team context has explored interactions between leader and follower characteristics and behaviors, such as research showing that the amount of effort put into the relationship by leaders and followers has implications for outcomes (Maslyn \& Uhl-Bien, 2001) and interactions between the attributional styles of leaders and followers (Martinko, Moss, Douglas, \& Borkowski, 2007). Cogliser, Schriesheim, Scandura and Gardner (in press) found that the degree to which leaders' and followers' agree on the quality of their relationships shape the context that influences outcomes.

\section{Social Networks}

Developing within sociology as a macro perspective concerning the structure of connections between entities, such as individuals, groups, and organizations, social network research has been extended to address micro-oriented issues surrounding the nature of relationships between people within and between organizations. For example, Brass and his colleagues (Brass, 1984, 1985; Burkhardt \& Brass, 1990) have 
demonstrated the importance of network position and influence in the organization.

Following from this research, Sparrowe and Liden (2005) showed that immediate leaders are instrumental in helping select followers with whom to establish broader social networks, which in turn, results in followers being seen by others in the organization has possessing influence. Although not using social network methods, per se, other research has demonstrated that the relationship that leaders have with their bosses influences the nature of relationships between leaders and followers (Graen, Cashman, Ginsburgh, \& Schiemann, 1977; Tangirala, Green, \& Ramanujam, 2007)

\section{Methods Advances}

To understand the role of context in leadership research, it is important to study variability in context. That is, despite a researcher's best intentions, it is impossible to disentangle the influence of context from other confounding effects if there is little or no variation across contexts (as well as variation in the possibly confounding effects that can be isolated and controlled). We are noting this point explicitly here because it is unfortunate to observe that in their quest to better understand a specific contextualized phenomenon some researchers (particularly from the qualitative perspective but not only) overly focus on phenomena in a particular context; even in qualitative research variation in cases is ideal and even sought for in order to establish patterns in the data (Eisenhardt \& Graebner, 2007). This suggestion has generally been ignored by case-study researchers.

It is clear that, given the dynamic and multi-faceted socio-environmental context in which leadership occurs, one cannot simply study leadership as one would simple chemical reactions, where ingredients can be added and subtracted at will and where 
there is complete experimental control. To understand the role of context, one needs variation across the contextual factor that is linked to variation in independent and dependent variables (or that moderates the relation between independent and dependent variables).

Advances in statistics needed for treating the context, such as the interplay between micro and macro organizational variables, has been instrumental in the dramatic increase in organizational behavior research that examines contextual issues. For example, developments in social network analysis have enabled researchers to model the dynamic patterns of relationships between individuals located within and between groups, and within and between organizations. Similarly, advances in multi-level analysis, such as the introduction of hierarchical linear modeling (fixed-effects, randomeffects and random-coefficients modeling) to the organizational sciences, has made it possible to more accurately capture the interplay between individuals, groups, and organizations. Most recently, multi-level structural equations modeling has made it possible to compare competing models containing variables measured at different levels of analysis (Zhang \& Willson, 2006). That said, there are still not enough studies that consider (or at least control for) macroeconomic or microeconomic fixed effects, or time effects that might be correlated with the variables under study (Bluedorn \& Jaussi, 2008). For example, to study the effect of CEO personality on organizational outcomes, one must study changes in CEOs in a particular firm, as well as variation of CEO personality within and between firms; also, the effects of firm size (or other firm-level factors) as well as industry and country-level factors must be partialed out before one can conclude that CEO personality has an effect on outcomes (Jacquart, Antonakis, \& Ramus, 2008). 


\section{Special Issue Articles Capturing the Context of Leadership}

Interestingly, articles in the current issue by Williams and Scandura and by Fry and colleagues, have addressed context at a micro level. This is in direct contrast to most previous research, which has portrayed the context through macro constructs, such as the environment in which organizations are embedded, including market conditions, scarcity of resources, and rate of change, as well as organizational structure, design, culture, and size. In this way, articles in our special issue make contributions toward more broadly defining the context in which leadership takes place.

Williams and Scandura (this issue) explore the role that LMX and coworker support play as key elements of the context surrounding team level mentoring, which occurs when leaders mentor all work group members en mass. The authors argue that in team settings, guidance, support, advice, and encouragement are best provided at the group, rather than the individual level. When work is organized at the team level, team mentoring is needed to achieve growth for the team as a whole. Although individual level mentoring is still needed to account for individual differences, for the team to move forward together, a team approach to mentoring allows for the leader to provide inspiration and coaching for all team members in unison. Williams and Scandura, in a departure from most characterizations of context, focus on individual relationships between coworkers and between the leader and each coworker as providing the context in which team mentoring takes place.

Fry and colleagues (this issue) characterize five levels of being as contexts for leadership. Basic to their arguments is the astute observation that because we refer to ourselves as human "beings," not human "doings" or human "havings," leadership should 
be based on sense of being, not on what a leader does or possesses. These authors contend that when leaders evolve to the point that they are able to incorporate a striving for truth, integrity, understanding of others, as well as demonstrations of love and sacrifice for others, the distinction between leaders and followers becomes blurred. The leader so effectively merges context with sense of being that followers do not discern that they are being led, but rather, they have become part of a whole that strives to help others in reaching the ultimate goals of sharing and concern for the welfare of others. Fry and colleagues present an approach to leadership that offers the potential for fully integrating context with self and self with others.

Cole, Bruch, and Shamir (this issue) look at how leader distance moderates the effects of transformational leadership and individual-leader outcomes. The Cole et al. study is one of the first to examine the differential effects of distance, an important contextual factor that has not been given serious attention by leadership scholars. Cole et al. investigated one specific form of social distance, hierarchical distance, to see whether it had an enhancing or a neutralizing effect on leader outcomes. Theoretically, distance might prevent the effects of some forms leadership (the neutralizing effect); concurrently and paradoxically, leadership might actually become more potent as distance increases (the enhancing effect). Data from 50 leader-follower groups across 26 business units showed a strong positive relation between subordinate transformational leadership and leader transformational leadership in a socially close context. However, when social distance was high there was no relation between leader transformational leadership and subordinate transformational leadership. They also found that the relation between transformational leadership and follower collective efficacy belief was stronger in high 
social distance situations. This, and other interesting findings, suggest that leadership has differential effects on relational- and collective-self as function of distance, and should hopefully inspire additional research linking different other forms of leader distance to follower outcomes.

\section{Future Research}

Despite the encouraging trend of increased attention placed on the context in leadership research, the vast majority of this research has focused on the influence of context on leadership or relationships between leadership and both individual and organizational outcomes. Relatively neglected has been the influence that individuals may have on the context. Schneider (1987) stressed this in his attraction-similarityattrition (ASA) paradigm when he presented his theory focusing on the way in which founding CEO characteristics typically result in the hiring of employees who share the values of the leader. Ultimately, the context of the organization is heavily influenced by individual characteristics of leaders and followers. Although some research has been conducted on the way in which leader characteristics and behaviors influence organizational culture (Schneider et al., 1995; Tsui et al., 2006), research is needed on founding CEOs to best test the ASA framework. Longitudinal designs capable of assessing the processes by which CEOs influence the emerging culture of the organization would be especially useful. For example, do CEOs shape the context of their organizations through their selection decisions, through their leader behaviors, or is it the interaction of selection and leader behavior that is most salient?

Great potential exists for research that further explores the ways in which the social context of teams influences leader behaviors, especially relationships formed between 
leaders and followers. Cogliser and colleagues' (in press) fresh approach of utilizing similarity in leader and follower perceptions of relationship quality as a variable offers the potential for many empirical investigations. Yet to be explored are associations between degree of effort exerted on behalf of the relationship and agreement on its subsequent quality. Also, to what extent does degree of LMX agreement relate to mutual trust between leader and follower? And what are the antecedents of differential levels of leader-follower agreement in LMX quality? One possibility is to explore the interpersonal and communication processes that result in varying degrees of agreement between leaders and followers on LMX quality.

Research on i-deals similarly offers a wealth of future research topics relevant to the team context in which leadership is embedded. For example, it would be fascinating to examine the way in which the negotiation of ideals relates to the formation of subgroups within the team. Social network methods might be used to explore such issues. It would also be interesting to explore perceptional processes involved in the influence of i-deals on team level variables, such as cohesion, cooperation, potency, and team effectiveness.

Within the realm of individual influences on the context, especially limited has been research attention devoted to the way in which followers influence leader behavior. Pioneering research by Herold (1977) and Lowin and Craig (1968) revealed that follower performance influences leader behaviors, House (1971) proposed that a leader must compensate for the situational variables, and follower individual differences, that affect whether followers can achieve their goals by changing the degree of initiating structure and consideration behavior that the leader displays. In later work, House (1996, p. 348) noted: "leaders, to be effective, engage in behaviors that complement subordinates' 
environments and abilities in a manner that compensates for deficiencies and is instrumental to subordinate satisfaction and individual and work unit performance." The approach taken by these researchers essentially treats follower characteristics and behaviors as representing an aspect of the context influencing leader behavior. Substantially more leadership research still emphasizes the effect of leader behavior on followers than on follower influences on leaders. Given the status differences between leaders and followers and the focus of leadership theories on the influence of leader behaviors on followers, this disproportion in types of research is appropriate. However, a complete understanding of leader behavior is only possible when taking follower characteristics and behaviors into consideration. Even research that does address followers tends to examine the way in which follower characteristics influence follower perceptions of leader behaviors (Schyns, Kroon, Moors, 2008; Yun, Cox, Sims, 2006). Needed is research exploring the processes through which followers affect the behavior of leaders (Riggio, Chaleff, \& Lipman-Blumen, 2008). For example, research has demonstrated that follower ingratiation (Wayne \& Ferris, 1990; Wayne \& Liden, 1995) and political behaviors (Ferris, Treadway, Perrewé, Brouer, Douglas, \& Lux, 2007) influence leader liking of followers as well as their performance ratings of followers. In a related vein, Tepper (2007) suggested that although supervisor abuse of subordinates may cause employees to engage in deviant behaviors, it is possible that deviant follower behaviors cause leaders to resort to abusive behavior in retaliation. In sum, research has just touched the surface regarding the many ways in which leaders and followers influence one another. 
Fry and colleagues (this issue) acknowledged that despite the promise of their approach for understanding leadership, the subjectivity of the focal concepts forming the foundation for the theory present a challenge for empirical research. Operationalizing constructs, such as the five levels of being, will certainly not be an easy task, especially studies with quantitative designs. The challenge is to attempt the assessment of deep feelings residing within leaders. The degree of subjectivity is such that the leaders themselves may not be aware of the way in which their inner soul or sense of being influences their behaviors towards followers.

Finally, although the development of sophisticated statistical methods for analyzing multi-level data capable of handling rich designs containing both "macro" and "micro" variables simultaneously have enabled researchers to better integrate the context into studies of leadership, the data requirements for such designs can be a challenge. Especially difficult are the requirements needed for the assessment of organizational level contextual variables. Such designs require an adequate sample at the organizational level. However, there is a known trade-off between the within and between-organizational sample sizes--a larger level 2 sample size can offset smaller level 1 sample sizes and vice-versa (Hofmann, 1997); refer to recent simulation work discussing power as well as inference in multilevel models (Maas \& Hox, 2005; Scherbaum \& Ferreter, 2009). Still, there are difficulties securing the permission to access 30-50 or more organizations, which should be sufficient to estimate multilevel models correctly. Conducting research that integrates individual and group levels of analysis, although still difficult, is more easily attainable, as researchers need access to only one organization if an adequate sample of groups is available to participate in the research. Alternatively, instead of 
accessing companies directly, researchers could find creative ways of studying leaders at a distance particularly for modeling organizational-level phenomena (e.g., see Simonton, 2003; Winter, 1991)

To conclude, we trust this special issue helps to advance the boundaries of leadership; future work should consider context in leadership research. 


\section{References}

Anand, S., Vidyarthi, P., Liden, R.C., \& Rousseau, D.M. (in press). Good citizens in poor quality relationships: Idiosyncratic deals as a substitute for relationship quality. Academy of Management Journal.

Antonakis, J., \& Atwater, L. (2002). Leader distance: A review and a proposed theory. The Leadership Quarterly, 13, 673-704.

Antonakis, J., Avolio, B. J., \& Sivasubramaniam, N. (2003). Context and leadership: An examination of the nine-factor full-range leadership theory using the Multifactor Leadership Questionnaire. The Leadership Quarterly, 14(3), 261-295.

Antonakis, J., Cianciolo, A. T., \& Sternberg, R. J. (2004). Leadership: Past, present, future. In J. Antonakis, A. T. Cianciolo \& R. J. Sternberg (Eds.), The Nature of Leadership (pp. 3-15). Thousand Oaks: Sage.

Antonakis, J., \& House, R. J. (2002). An analysis of the full-range leadership theory: The way forward. In B. J. A. F. J. Yammarino (Ed.), Transformational and Charismatic Leadership: The Road Ahead (pp. 3-34). Amsterdam: JAI Press.

Antonakis, J., Schriesheim, C. A., Donovan, J. A., Gopalakrishna-Pillai, K., Pellegrini, E., \& Rossomme, J. L. (2004). Methods for studying leadership. In J. Antonakis, A. T. Cianciolo \& R. J. Sternberg (Eds.), The Nature of Leadership (pp. 48-70). Thousand Oaks: Sage.

Bacharach, S. B. (1989). Organizational theories: Some criteria for evaluation. Academy of Management Review, 14(4), 496-515.

Bass, B. (1997). Does the transactional - transformational leadership paradigm transcend organizational and national borders? American Psychologist, 52, 130-139. 
Bass, B. M., Avolio, B. J., Jung, D. I., \& Berson, Y. (2003). Predicting unit performance by assessing transformational and transactional leadership . Journal of Applied Psychology, 88, 207-218.

Blair, J. D., \& Hunt, J. G. (1986). Getting inside the head of the management researcher one more time: Context-free and context-specific orientations in research. Journal of Management, 12, 147-166.

Bluedorn, A. P., \& Jaussi, K. S. (2008). Leaders, followers, and time. Leadership Quarterly, 19, 654-668.

Boies, K., \& Howell, J. M. (2006). Leader-member exchange in teams: An examination of the interaction between relationship differentiation and mean LMX in explaining team-level outcomes. Leadership Quarterly, 17, 246-257.

Brass, D. J. (1984) Being in the right place: A structural analysis of individual influence in an organization. Administrative Science Quarterly, 29, 518-539.

Brass, D. J. (1985). Men's and women's networks: A study of interaction patterns and influence in an organization. Academy of Management Journal, 28, 327-343.

Burkhardt, M. E., and D. J. Brass (1990). Changing patterns or patterns of change: The effects of a change in technology on social network structure and power." Administrative Science Quarterly, 35, 104-127.

Cogliser, C. C., \& Schriesheim, C. A. (2000). Exploring work unit context and leadermember exchange: A multi-level perspective. Journal of OrganizationalBehavior,21, 487-511. 
Cogliser, C. C., Schriesheim, C. A., Scandura, T. A., \& Gardner, W. L. (in press). Balance in leader and follower perceptions of leader-member exchange: Relationships with performance and work attitudes. Leadership Quarterly.

Coles et al this issue

Dickson, M. W., Den Hartog, D. N., \& Mitchelson, J. K. (2003). Research on leadership in a cross-cultural context: Making progress, and raising new questions. Leadership Quarterly, 14, 729-768.

Dienesch, R.M., \& Liden, R.C. (1986). Leader-member exchange model of leadership: A critique and further development. Academy of Management Review, 11, 618-634.

Dorfman, P. W., Howell, J. P., Hibino, S., Lee, J. K., Tate, U., \& Bautista, A. (1997). Leadership in Western and Asian Countries: Commonalities and Differences in Effective Leadership Processes Across Cultures. Leadership Quarterly, 8(3), 233274.

Dubin, R. (1976). Theory building in applied areas. In M. D. Dunnette (Ed.), Handbook of Industrial and Organizational Psychology (pp. 17-40). Chicago: Rand McNally.

Eisenhardt, K. M., \& Graebner, M. E. (2007). Theory building from cases: Opportunities and challenges. Academy of Management Journal, 50(1), 25-32.

Endler, N. S., \& Magnusson, D. Toward an interactional psychology of personality. Psychological Bulletin, 83, 956-974, 1976.

Epstein, S. The stability of behavior: Implications for psychological research. American Psychologist, 35, 790-806, 1980.

Erdogan, B., \& Liden, R. C. (2002). Social exchanges in the workplace: A review of recent developments and future research directions in leader-member exchange 
theory. In L. L. Neider and C. A. Schriesheim (Eds.), Leadership (pp. 65-114).

Greenwich, CT: Information Age Publishing.

Erdogan, B., \& Liden, R.C. (2006). Collectivism as a moderator of responses to organizational justice: Implications for leader-member exchange and ingratiation. Journal of Organizational Behavior, 27, 1-17.

Erdogan, B., Liden, R. C., \& Kraimer, M. L. (2006). Justice and Leader-Member Exchange: The Moderating Role of Organizational Culture. Academy of Management Journal, 49, 395-406.

Ferris, G.R., Treadway, D.C., Perrewé, P.L., Brouer, R.L., Douglas, C., \& Lux, S. (2007). Political skill in organizations. Journal of Management, 33, 290-320.

Fry et al this issue

Gelfand, M. J., Erez, M., \& Aycan, Z. (2007). Cross-Cultural Organizational Behavior. Annual Review of Psychology, 58, 479-514.

Graen, G., Alvares, K., Orris, J. B., \& Martella, J. A. Contingency model of leadership effectiveness: Antecedent and evidential results. Psychological Bulletin, 74, 285-296, 1970.

Graen, G. B., Cashman, J. F., Ginsburgh, S., \& Schiemann, W. (1977). Effects of linkingpin quality on the quality of working life of lower participants. Administrative Science Quarterly, 22, 491-504.

Hanges, P. J., Schneider, B., \& Niles, K. Stability of performance: An interactionist perspective. Journal of Applied Psychology, 75, 658-667, 1990. 
Henderson, D. J., Liden, R.C., Glibkowski, B.C. \& Chaudhry, A. (2009). Within-group LMX differentiation: A multilevel review and examination of its antecedents and outcomes. Leadership Quarterly, 20, 517-534.

Henderson, D. J., Wayne, S. J., Shore, L. M., Bommer, W. H., \& Tetrick, L. E. (2008). Leader-member exchange, differentiation, and psychological contract fulfillment: A multilevel examination. Journal of Applied Psychology, 93, 1208-1219.

Herold, D. M. (1977). Two-way influence processes in leader-follower dyads. Academy of Management Journal, 20, 224-237.

Hofmann, D. A. (1997). An overview of the logic and rationale of hierarchical linear models. Journal of Management, 23(6), 723-744.

House, R. J. (1971). A path-goal theory of leadership effectiveness. Adminstrative Science Quarterly, 16.

House, R. J. (1996). Path-goal theory of leadership: Lessons, legacy, and a reformulated theory. Leadership Quarterly, 7(3), 323-352.

House, R. J., Hanges, P. J., Mansour, J., Dorfman, P. W., \& Gupta, V., Eds. (2004).

Culture, leadership, and organizations: The GLOBE study of 62 societies. Thousand Oaks, CA: Sage.

Jacquart, P., Antonakis, J., \& Ramus, C. (2008). Does CEO personality matter? Implications for financial performance and corporate social responsibility. International Journal of Psychology, 43(3-4), 596-596.

James, L. A., \& James, L. R. Integrating work environment perceptions: Explorations into the measurement of meaning. Journal of Applied Psychology, 74, 739-751, 1989.

Johns, G. (2001). In praise of context. Journal of Organizational Behavior, 22, 31-42. 
Johns, G. 2006. The essential impact of context on organizational behavior. Academy of Management Review, 31, 386-408.

Lai, L., Rousseau, D.M., \& Chang, T.T. (in press). Idiosyncratic deals: Coworkers as interested third parties. Journal of Applied Psychology.

Lau, D.C., \& Liden, R.C. (2008). Antecedents of coworker trust: Leaders' blessings. Journal of Applied Psychology, 93, 1130-1138.

Lester, S. W., Meglino, B. M., \& Korsgaard, M.A. (2002). The antecedents and consequences of group potency: A longitudinal investigation of newly formed work groups. Academy of Management Journal, 45, 352-368.

Lewin, K. (1947). Frontiers in group dynamics: Concept, method and reality in social science; Social equilibria and social change. Human Relations, 1, 4-41.

Lewin, K., \& Lippitt, R. An experimental approach to the study of autocracy and democracy: A preliminary note. Sociometry, 1938, 1, 292-300.

Liden, R.C., Erdogan, B., Wayne, S.J., \& Sparrowe, R.T. (2006). Leader-member exchange, differentiation, and task interdependence: Implications for individual and group performance. Journal of Organizational Behavior, 27, 723-746.

Liden, R. C., Sparrowe, R. T., \& Wayne, S. J. 1997. Leader-member exchange theory: The past and potential for the future. Research in Personnel and Human Resources Management, 15: 47-119.

Lim, B. C., \& Ployhart, R. E. (2004). Transformational leadership: Relations to the fivefactor model and team performance in typical and maximum contexts. Journal of Applied Psychology, 89(4), 610-621. 
Ling, Y., Simsek, Z., Lubatkin, M. H., \& Veiga, J. F. (2008). The impact of transformational CEOs on the performance of small- to medium-sized firms: Does organizational context matter? Journal of Applied Psychology, 93, 923-934.

Lord, R. G., Brown, D. J., Harvey, J. L., \& Hall, R. J. (2001). Contextual Constraints on Prototype Generation and their Multilevel Consequences for Leadership Perceptions. Leadership Quarterly, 12, 311-338.

Lord, R. G., Foti, R. J., \& De Vader, C. L. (1984). A Test of Leadership Categorization Theory: Internal Structure, Information Processing, and Leadership Perceptions. Organizational Behavior and Human Performance, 34, 343-378.

Lowe, K. B., Kroeck, K. G., \& Sivasubramaniam, N. (1996). Effectiveness correlates of transformation and transactional leadership: A meta-analytic review of the MLQ literature. Leadership Quarterly, 7, 385-425.

Lowin, A., \& Craig, J. R. (1968). The influence of level of performance on managerial style: An experimental object-lesson in the ambiguity of correlation data. Organizational Behavior and Human Performance, 3, 440-458.

Maas, C. J. M., \& Hox, J. J. (2005). Sufficient Sample Sizes for Multilevel Modeling. Methodology: European Journal of Research Methods for the Behavioral and Social Sciences, 1, 85-91.

Martinko, M. J., Moss, S. E., Douglas, S. C. \& (2007). Anticipating the inevitable: When leader and member attributional styles clash. Organizational Behavior and Human Decision Processes, 104, 158-174. 
Mischel, W. (1977). The interaction of person and situation. In D. Magnusson \& D. Endler (Eds.), Personality at the crossroads: Current issues in interactional psychology (pp. 333-352). Hillsdale, NJ: Lawrence Erlbaum associates, Publishers.

Morgeson, F. P. (2005). The external leadership of self-managing teams: Intervening in the context of novel and disruptive events. Journal of Applied Psychology, 90, 497508.

Morgeson, F. P., \& DeRue, D. S. (2006). Event criticality, urgency, and duration: Understanding how events disrupt teams and influence team leader intervention. Leadership Quarterly, 17, 271-287.

O’Reilly, C. A., Chatman, J., \& Caldwell, D. F. (1991). People and organizational culture: A profile comparison approach to assessing person-organization fit. Academy of Management Journal, 34, 487-516.

Ostroff, C. The relationship between satisfaction, attitudes, and performance: An organizational level analysis. Journal of Applied Psychology, 77, 963-974, 1992.

Porter, L. W., \& McLaughlin, G. B. (2006). Leadership and the organizational context: Like the weather? Leadership Quarterly, 17, 559-576.

Riggio, R. E., Chaleff, I., \& Lipman-Blumen, J. (Eds.) (2008). The art of followership. San Francisco, CA: Jossey-Bass.

Rousseau, D.M., \& Fried, Y. 2001. Location, location, location: Contextualizing organizational research. Journal of Organizational Behavior, 22: 1-13.

Sashkin, M. (2004). Transformational leadership approaches: A review and synthesis. In J. Antonakis, A. T. Cianciolo \& R. J. Sternberg (Eds.), The Nature of Leadership (pp. 171-196). Thousand Oaks: Sage. 
Schein, E. H. (1990). Organizational culture. American Psychologist, 45, 109-119.

Scherbaum, C. A., \& Ferreter, J. M. (2009). Estimating Statistical Power and Required Sample Sizes for Organizational Research Using Multilevel Modeling. Organizational Research Methods, 12(2), 347-367.

Schneider, B. (1987). The people make the place. Personnel Psychology, 40, 437-453. Schriesheim, C. A., \& Kerr, S. (1977). Theories and measures of leadership: A critical appraisal of current and future directions. In J. G. Hunt \& L. L. Larson (Eds.), Leadership: The cutting edge (pp. 9-45). Carbondale: Southern Illinois University Press.

Schriesheim, C. A., Tepper, B. J., \& Tetrault, L. A. (1994). Least preferred co-worker score, situational control and leadership effectiveness: A meta-analysis of contingency model performance predictions. Journal of Applied Psychology, 79(4), $561-573$

Schriesheim, C. A., Castro, S. L., \& Cogliser, C. C. (1999). Leader-member exchange (LMX) research: A comprehensive review of theory, measurement, and data-analytic practices. Leadership Quarterly, 10, 63-113.

Schneider, B. (1987). The people make the place. Personnel Psychology, 40, 437-453.

Schneider, B., Goldstein, H. W., \& Smith, D. B. (1995). The ASA framework: An update. Personnel Psychology, 48, 747-773.

Schyns, B., Kroon, B., \& Moors, G. (2008). Follower characteristics and the perception of leader-member exchange. Journal of Managerial Psychology, 23, 772-788.

Shamir, B. (1995). Social Distance and Charisma - Theoretical Notes and an ExploratoryStudy. Leadership Quarterly, 6(1), 19-47. 
Shamir, B., \& Howell, J. M. (1999). Organizational and contextual influences on the emergence and effectiveness of charismatic leadership. Leadership Quarterly, 10, $257-283$.

Simonton, D. K. (2003). Qualitative and Quantitative Analyses of Historical Data. Annual Review of Psychology, 54, 617-640.

Sparrowe, R.T., \& Liden, R.C. (2005). Two routes to influence: Integrating leadermember exchange and network perspectives. Administrative Science Quarterly, 50, $505-535$.

Tepper, B. J. (2007). Abusive supervision in work organizations: Review synthesis, and research agenda. Journal of Management, 33, 261-289.

Tse, H. H. M., Dasborough, M. T., \& Ashkanasy, N. M. (2008). A multi-level analysis of team climate and interpersonal exchange relationships at work. Leadership Quarterly, 19, 195-211.

Tsui, A. S., Zhang, Z. X. Wang, H. Xin, K. R.\& Wu, J. B. (2006). Unpacking the relationship between CEO leadership behavior and organizational culture. Leadership Quarterly, 17, 113-137.

Vecchio, R. P. An empirical examination of the validity of Fiedler's model of leadership effectiveness. Organizational Behavior \& Human Performance, 19, 180-206, 1977).

Waldman, Y. (1999). CEO charismatic leadership: levels-of-management and levels-ofanalysis. Academy of management review, 266(2).

Wayne, S. J., \& Ferris, G. R. (1990). Influence tactics, affect, and exchange quality in supervisor-subordinate interactions. Journal of Applied Psychology, 75, 487-499. 
Wayne, S.J., \& Liden, R.C. (1995). Effects of impression management on performance ratings: A longitudinal study. Academy of Management Journal, 38, 232-260.

Weber, M. (1947). The theory of social and economic organization (T. Parsons, Trans.). New York: The Free Press.

Williams \& Scandura this issue

Winter, D. G. (1991). Measuring personality at a distance: Development of an integrated system for scoring motives in running text. In A. J. Stewart, H. J. J. M. \& O. D. J. (Eds.), Perspectives in personality, Vol. 3, Part B: Approaches to understanding lives (pp. 59-89. ). London: Jessica Kingsley Publishers.

Yun, Cox, \& Sims, H. P., Jr. (2006). The forgotten follower: A contingency model of leadership and follower self-leadership. Journal of Managerial Psychology, 21, 374388.

Zaccaro, S. J., Kemp, C., \& Bader, P. (2004). Leader traits and attributes. In J. Antonakis, A. T. Cianciolo \& R. J. Sternberg (Eds.), The Nature of Leadership (pp. 101-124). Thousand Oaks: Sage.

Zaccaro, S. J., \& Klimoski, R. J. (2001). The nature of organizational leadership. In S. J. Zaccaro \& R. J. Klimoski (Eds.), The nature of organizational leadership. (pp. 3-41). San Francisco: Jossey-Bass Publishers.

Zhang, D., \& Willson, V. L. (2006). Comparing empirical power of multilevel structural equation models and hierarchical linear models: Understanding cross-level interactions. Structural Equation Modeling, 13, 615-630. 